\title{
Insulating Electric Cables
}

In 1730, Stephen Gray, a Charterhouse Pensioner (a retired member of an austere monastic order in France), first transmitted electricity along a thread made of hemp some 270 meters in length. He dampened the thread to increase conductivity and suspended it by silk in order to provide insulation. Aside from Benjamin Franklin's earlier experiments with lightning discharges, this event is acknowledged as the birth of cables capable of carrying weak electrical currents, from which grew power lines.

Early power cables were known as "conductors," while the term "cable" was reserved for telegraph and telephone lines. Eventually, rigid conductors were called "mains," and flexible power conductors were included as "cables."

In England, 17 years after Gray's initial experiments, William Watson transmitted current over a 3.2-kilometer-long metal wire, completing the circuit by using the earth as a ground to transmit the return current. As a slightly "shocking" sidelight, Watson's assistant later demonstrated the electrifying result of that particular circuit when completing the connection by holding onto the far end of the wire with one hand and plunging a metal rod into the River Thames with the other hand-_"completely vindicat[ing] the result which had been anticipated." Yet, the chief scientist, not the assistant, is remembered.

Although not fully recognized at that time, the major problem with electric cables would not be the conductor that carried the current, but with the material insulating the conductor. Simon Linguet explored the insulation of cables. In 1782, unhindered by his imprisonment in the Bastille, the French lawyer wrote of transmitting electric current along "gilded iron wires enclosed in wooden tubes filled with resin and buried underground."

Don Francisci Salva further advanced the state of cable insulation in an article presented to the Academy of Science in Barcelona in 1795. Salva covered 22 wires with paper, coated them with pitch, and after tying them together, bound them further with additional paper. In 1798 Salva succeeded in transmitting effective signals by means of electrostatic discharges over a 42-kilometer-long cable of this design. As an alternative to stringing the wires overhead, Salva suggested twisting the wires together and laying them underground in subterranean tubes.

Between the years of 1812 and 1815 Baron von Schilling developed a copper wire cable insulated by India-rubber, which was then dried and varnished. Von Schilling was heavily influenced by Robert Fulton's idea of detonating explosives by using electricity. Described by von Schilling as a "conducting cord," the cables were used to detonate mines beneath the River Neva and River Seine during the Napoleonic Wars. These can be called the first true electric power cables.

Keeping moisture away from the conductor so as to not short the circuit remained a continuing problem. An early solution to this problem was found through a substance called gutta-percha, discovered on the Malaya peninsula. The first use in England of gutta-percha, a natural thermoplastic material made from the milk of a tree indigenous to Singapore, was documented in the literature by John Tradescant the Younger in 1656. Guttapercha was later reintroduced into Europe in 1843 by the Scottish surgeon William Montgomerie. Gutta-percha had insulating properties similar to natural rubber, but had a tough, hornlike texture at room temperature. In addition, it was easily processed when heated, allowing it to be readily pressed into tubing.

Several leading scientists, including Michael Faraday, experimented with the properties of gutta-percha. The substance was quickly recognized as a way to insulate both underground and underwater cables.

By 1847 Werner Siemens in Berlin invented a sheathing process using guttapercha that produced over 4,800 kilometers of insulated telegraph wire for the Persian Post Office. However, gutta-percha's sensitivity to oxidation and its tendency to soften at high temperatures resulted in failures when the cables were used on land. This was overcome by wrapping the cables in jute (a strong, coarse fiber used for making burlap) and drawing them into iron pipes to contain the softened material.

In 1880, in Philadelphia, David Brooks insulated copper wire with Manilla hemp strands and drew them through an oilfilled wrought-iron pipe. This process eventually evolved into today's dry-core cables, which are insulated by dry cellulose or polyethylene.

Additional methods of insulating cables were invented in the 1800 s as power systems continued to evolve. In 1839 , Indiarubber was vulcanized by treating it under heat with sulphur to render it nonplastic and thus give it greater elasticity. It was used extensively starting in 1888 when it became a recognized standard for insulating electric cables, mostly due to a decision by the New York Subway Commission to use vulcanized-rubber cables that had been sheathed with lead and then drawn into ducts.

Lugigi Emanueli refined David Brooks's experiments with insulating oil and in 1917 Emanueli's patent for an oil-filled cable spun off numerous designs for oilfilled cables. In 1925 Fisher and Atkinson proposed the gas-pressurized cable, a concept that raised the electrical breakdown strength of the cable by subjecting the dielectric to dry compressed air; this also led to many other forms of gas-pressurized cables.

Today, techniques such as irradiating polyethylene with electrons, gamma rays, $\mathrm{X}$-rays, protons, or alpha particles (called radiation crosslinking), produce rubberlike properties in polyethylene, such as elasticity. This has profound consequences in power transmission by making better insulation.

DOUG BEASON

For FurTher REAdING: P.V. Hunter and J.T. Hazell, Development of Power Cables (London, 1956).

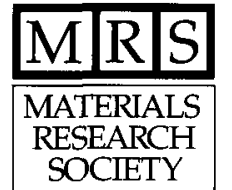

Please update your address for the MRS 1995 Membership Directory. Deadline: May 15, 1995

Fax 412-367-4373

E-mail: INFO@MRS.ORG 